\title{
La reflexión y la crítica católica en la prensa cinematográfica bajo el franquismo. Del nacional-catolicismo a Ingmar Bergman
}

\author{
Jorge NiETO FERRANDO \\ Universitat de Lleida \\ nietojordi@filcat.udl.cat
}

Recibido: 24 de noviembre de 2011

Aceptado: 25 de junio de 2012

\begin{abstract}
Resumen
Este artículo aborda la reflexión católica en la prensa cinematográfica bajo la dictadura franquista. Con un papel destacado en la educación, los medios de comunicación y la cultura, los supuestos de la iglesia católica sobre la pantalla cinematográfica discurrirán del anatema a los intentos de analizar su funcionamiento como fenómeno, en especial su influencia sobre la infancia y la juventud, y la elaboración de unos supuestos críticos que permitan destacar las películas con valores asumibles. En el ámbito de la reflexión será fundamental la Filmología, que contará con un departamento en el Centro Superior de Investigaciones Científicas; en lo referente al ejercicio crítico, los católicos reformularán y adaptarán a sus supuestos los principales paradigmas críticos de cada momento.
\end{abstract}

Palabras clave: Prensa cinematográfica, teoría y crítica del cine, nacionalcatolicismo, Federico Fellini, Ingmar Bergman.

\section{Catholic reflection and criticism in the film press under Franco Dictatorship. From National Catholicism to Ingmar Bergman}

\begin{abstract}
This article discusses Catholic reflection in the film press under the Franco dictatorship. With a leading role in education, media and culture, the assumptions of the Catholic Church on the silver screen would be anathema to attempts to analyse their operation as a phenomenon, especially their influence on children and young people and the development of some critical assumptions that enabled highlighting films with assumed values. Filmology will be essential in the field of reflection, which will involve a department at the Higher Centre for Scientific Research. With regards to critical exercise, the Catholics will reformulate and adapt main critical paradigms to their assumptions in each moment.

Keywords: Film press, film theory and criticism, National Catholicism, Federico Fellini, Ingmar Bergman

Referencia normalizada: NIETO FERRANDO, Jorge (2012): "La reflexión y la crítica católica en la prensa cinematográfica bajo el franquismo. Del nacional-catolicismo a Ingmar Bergman". Estudios sobre el mensaje periodístico, vol. 18, núm. 2 (julio-diciembre), págs.: 855-873. Madrid, Servicio de Publicaciones de la Universidad Complutense.
\end{abstract}

Sumario: 1. Introducción. 2. Reflexión. La Filmología. 3. Crítica. Del nacionalcatolicismo a Bergman. 4. Conclusión. 5. Referencias bibliográficas.

\section{Introducción}

No hay duda de que la influencia de la iglesia católica y su ideario en el cine español bajo el franquismo fue determinante. Con un papel clave en la legitimación y justificación de la victoria de los sublevados y amplios intereses en la educación, la cultura y la comunicación -enfrentados en más de una ocasión con otros grupos vencedores como los falangistas-, intervendría de manera significativa en la configuración de las 
instituciones cinematográficas del nuevo régimen, al mismo tiempo que aportaba a muchas películas temas relacionados con su historia, actividades, ritos y mitología ${ }^{1}$, conformaba un grupo de presión muy influyente, capaz de ensombrecer o ensalzar películas en función de si consideraba que atacaban, defendían o simplemente eran compatibles con sus valores, incitaría a la intervención de los feligreses en la industria con productoras que podían acercarse a sus intereses -Estela Films, Aspa Films o Procusa-, en la educación cinematográfica de los espectadores mediante sus cineclubs -Vinces y Monterols, por ejemplo- y publicaciones especializadas -Revista Internacional del Cine, Film Ideal, Documentos Cinematográficos o Cinestudio, entre las más destacadas-, e intentaría canalizar la con anterioridad considerada perniciosa influencia del cine en virtuosa función, en instrumento de proselitismo. Todo esto va mucho más allá de la postura bronca, anatematizadora y esquinada que en ocasiones, no sin cierta razón, se le ha atribuido en la materia. A pesar de ello, de la importancia del catolicismo en la vida cinematográfica española en este periodo, pocas veces ha despertado la atención continuada por parte de los historiadores del cine o la cultura ${ }^{2}$.

La acción de la iglesia católica sobre el cine adquiere una importancia destacada a nivel internacional con la encíclica Vigilanti Cura (29 de junio de 1936) y las actividades de la Oficina Católica Internacional del Cine (OCIC). La encíclica muestra el singular maridaje entre las posiciones católicas reaccionarias, preeminentes en las primeras y deshilvanadas aproximaciones del clero al medio, que parten del peligro que supone toda modernidad e inciden en los supuestos problemas fisiológicos, psicológicos y morales de la pantalla cinematográfica, y las regeneracionistas más orientadas a señalar que su maldad puede tornarse en virtud, pues el pecado no reside tanto en la naturaleza del cine como en el uso que recibe, por lo que puede canalizarse un una dirección acorde con los supuestos católicos (DíEz PuerTAS, 2002:111). Serán los planteamientos regeneracionistas los que al final se impongan, sobre todo desde finales de los años cuarenta. Dentro de estos pueden incluirse los discursos de Pío XII en junio y octubre de 1955 -considerado desde entonces el 'Papa del Cine'-, que complementan la encíclica y serían reproducidos en los números 17-18 (1955a) y 21-22 (1955b) de Revista Internacional del Cine con los títulos "Características del Film Ideal" y "El cine debe estar al servicio del hombre", además de motivar el nombre de la revista Film Ideal, o la encíclica Miranda Prorsus (1957), aunque esta última haga referencia con carácter más general a los medios de comunicación de masas. Por su parte, la OCIC nace en 1928 con el fin de aglutinar y coordinar las actividades de las

\footnotetext{
${ }^{1}$ Los ejemplos son numerosos, y van desde las apologías de las misiones -Misión blanca (Juan de Orduña, 1946) o La mies es mucha (José Luis Sáenz de Heredia, 1948)- hasta películas con argumentos extraídos de los evangelios -El beso de Judas (Rafael Gil, 1953)- o del santoral -La señora de Fátima (Rafael Gil, 1951) o Teresa de Jesús (Juan de Orduña, 1962)-, pasando, lo que es más frecuente, por otras tantas que destacan la intervención de los ministros de la Iglesia en toda suerte de enredos mundanos, a los que aplicarán su bondad, sabiduría y buen hacer: Balarrasa (José Antonio Nieves-Conde, 1950), Cerca de la ciudad (Luis Lucia, 1952) o La guerra de Dios (Rafael Gil, 1953).

${ }^{2}$ Más allá de algunos análisis puntuales, la excepción sería el singular e importante trabajo de Juan Antonio MARTínez BRETón (1988).
} 
distintas asociaciones católicas con intereses en el cine. Su fundador y primer director será monseñor Abel Brohée. En uno de sus primeros congresos internacionales de estudios, celebrado en Bruselas en septiembre de 1933, la OCIC acordará tres líneas fundamentales de actuación por parte de los católicos sobre el cine: la introducción en la producción cinematográfica, la creación de circuitos de distribución y exhibición de películas católicas y la orientación de los espectadores mediante la publicación en la prensa católica de críticas de películas centradas en su contenido moral.

Estas líneas son retomadas y ampliadas en reuniones posteriores, sobre todo en la posguerra mundial. Destacan en lo concerniente a este artículo las que analizarán la crítica de cine (Lucerna, mayo de 1951), la formación cinematográfica del espectador (Madrid, mayo de 1952) o la promoción de las denominadas "buenas películas" (París, junio de 1958). Las últimas serán aquellas que demuestren la pericia del director en el uso de los recursos formales y técnicos, aborden contenidos interesantes y, en especial, se ajusten de alguna manera al canon moral y religioso defendido por la Iglesia entendido en un sentido laxo, sin por ello necesariamente abordar temas exclusivos de ésta. El nexo de unión de estas tres cuestiones será la crítica, cuyo papel es formar al espectador -junto a la escuela y el cineclub- y promocionar las buenas películas. El objetivo es convertir al católico en un espectador avezado, dotado de los instrumentos necesarios para encarar los perjuicios de las películas y, al mismo tiempo, en un espectador exigente que, unido al resto del público católico, puede llegar a configurar un grupo de presión -con incidencia en la taquilla- capaz de condicionar las decisiones de la industria cinematográfica con la exigencia de películas aceptables ${ }^{3}$. Con ello se hará innecesaria la censura, dada la mala imagen que su ejercicio genera, ya que el espectador aprenderá a autoprotegerse.

Al mismo tiempo, los católicos también irán dotándose de instrumentos que les permitirán apreciar de manera más ajustada la actividad que los espectadores desarrollan a la hora de enfrentarse a la pantalla cinematográfica, y a partir de ello calibrar hasta qué punto los prejuicios tradicionales ante el cine -especialmente con públicos menores de edad- son o no acertados, además de intentar tornar la peligrosa influencia del cine en loable función. Será la Filmología desde principios de los años cincuenta la disciplina que satisfaga estas necesidades, y dotará de cierta aura de cientificidad a las reflexiones católicas sobre cine.

\section{Reflexión. La Filmología}

La Filmología constituye uno de los primeros intentos de reflexionar sistemática y metodológicamente sobre el hecho fílmico y cinematográfico más allá de la reflexión

\footnotetext{
${ }^{3}$ Algunos artículos de Revista Internacional del Cine enfatizan el enorme poder de los católicos como grupo de presión (VV. AA, 1959) e insisten en mantener un "Frente cerrado contra el fango", como señala el texto publicado en el número 42 (G.S., 1963): "Si los católicos que nos consideramos practicantes y disciplinados siguiéramos las orientaciones de la Iglesia en materia de espectáculos, la inmoralidad se acabaría al acabarse el negocio. Si los católicos ayudáramos a las películas buenas, los directores no se desviarían a la izquierda, porque la inmensa masa de clientes católicos es siempre decisiva".
} 
impresionista o de las propuestas que buscan dilucidar la naturaleza del cine. La Filmología hace un llamamiento a disciplinas como la psicología, la sociología o la lingüística susceptibles de tomar al cine entre sus objetos de investigación. Su principal impulsor será Gilbert COHEN-SEAT, que en 1946 publica Essai sur les principes d'une philosophie du cinéma y funda la Association Française pour la Recherche Filmologique y, al año siguiente, Revue Internationale de Filmologie. En ella colaborarán Roger Caillois, Edgar Morin, Henri Agel o Roland Barthes, entre muchos otros. El Primer Congreso Internacional de Filmología, celebrado en septiembre de 1947, definirá una serie de ámbitos en los que concentrar los análisis, entre los que destacarán la investigación psicológica, en especial desde el punto de vista experimental, las aproximaciones estéticas y sociológicas, o la aplicación de sus análisis a los problemas de la enseñanza y la psicología clínica (LOWRY, 1985: 49-53).

El cine ya es un objeto dado, y las reflexiones se encaminan no tanto a descubrir su naturaleza como a analizar su funcionamiento como fenómeno. Los intereses están centrados fundamentalmente en la recepción filmica, en lo que los filmólogos denominan la "situación cinematográfica", formada por el conjunto de la sala, la pantalla y el espectador, donde tienen lugar distintos procesos como la percepción del movimiento, el disfrute de la historia, su participación en ella, la aplicación de la memoria en el proceso de espectación o la identificación con la peripecia, sin olvidar la distinta disposición de los espectadores a la hora de enfrentarse a las películas o sus gustos personales.

Entre los trabajos fundamentales de la corriente destacan las aproximaciones a la percepción de la imagen en la pantalla de Henri WALLON (1953) ${ }^{4}$, a los procesos de comprensión de René y Bianka ZAZzo (1949), a la participación espectatorial de Albert MichotTe (1953) o la perspectiva sociológica que propondrán Georges FriedMANN y Edgar MORIN (1952 y 1955). Muchos de estos planteamientos estarán introducidos en L'univers filmique (1953), de Étienne SOURIAU ${ }^{5}$.

La Filmología nacerá en un ambiente marcado por el predominio de la fenomenología, en especial en la versión de MERLEau PONTY, y sin duda se verá muy influido por ella. A partir de los supuestos e intereses apuntados, la nueva disciplina -o compendio de disciplinas-, que permanecerá activa fundamentalmente en los años cincuenta y parte de los sesenta, elabora reflexiones muy especializadas, consensuando un terminología teórica para enfrentarse a la pantalla alejada del lenguaje común con algunos tecnicismos empleado hasta el momento -define, por ejemplo, los términos 'profílmico' y 'diegético', asumidos más adelante por buena parte de los teóricos del cine-, y toma distancia respecto a la actividad crítica y a la práctica cinematográfica, actividades con las que la reflexión sobre el cine siempre había establecido estrechos lazos. Con la Filmología estas reflexiones adquieren un grado importante de rigor, y el esfuerzo por ser sistemático supera a la intuición más o menos acertada.

Los filmólogos se mostrarán muy proselitistas, irradiando sus ideas por toda Europa. Estas germinarán sobre todo entre sectores católicos interesados en el cine. De

4 A este habría que añadir las aportaciones de Albet Michotte (1948), A. Rey (1954) o Dario ROMANO (1965).

5 Para una aproximación más detallada a sus propuestas véase LOWRY (1985). 
hecho, la Filmología permitirá alcanzar uno de los objetivos fundamentales de su cambio de actitud ante la pantalla a finales de los años cuarenta, su apuesta decidida por el regeneracionismo: conocer con profundidad los resortes del cine en relación con el espectador, especialmente en el ámbito psicológico, para poder afrentarse a él sin caer en el simple anatema, incluso aprender a utilizarlo con fines proselitistas. En España esta disciplina será cultivada por la Asociación Española de Filmología (AEF), el Instituto de Investigaciones y Experiencias Cinematográficas (IIEC), que tendrá una asignatura sobre la materia en sus años iniciales, y el Departamento de Filmología del Centro Superior de Investigaciones Científicas (CSIC). La primera se constituye en 1949 y estará dirigida por José Germain. En su junta directiva aparecen críticos y profesionales del cine como Carlos Fernández Cuenca, Carlos Serrano de Osma, Julián Marías, Fernando Fernán-Gómez, José López Rubio y fray Mauricio de BEGOÑa. Algún tiempo más tarde será constituida en Barcelona una delegación de la Asociación, dirigida por Guillermo Díaz-Plaja y con Sebastián Gasch, Tomás Gutiérrez-Larraya, Domingo Giménez, Juan Francisco de Lasa, Jerónimo de Moragas, María Luz Morales, José Palau y Ángel Zúñiga, sin duda lo más granado de la crítica cinematográfica catalana del momento, en su junta directiva. Las informaciones sobre esta asociación publicadas en la prensa de la época denotan una vida limitada a impartir conferencias y organizar ciclos de películas ${ }^{6}$, muchas veces en coordinación con el IIEC. Así sucede, por ejemplo, con la visita a Madrid de Enrico FulChignONI a principios de diciembre de 1949, presentado como director del Instituto de Psicología de la Universidad de Roma y uno de los filmólogos italianos más influyentes, para impartir las conferencias "El film como test proyectivo" "La imagen colectiva del film" y "La enseñanza de la historia a través del cine", organizadas por la AEF y el IIEC ${ }^{7}$. Además, Fray Mauricio de BEGOÑA, que poco más tarde escribirá su famoso Elementos de Filmología (1953), formará parte de la primera y será profesor de la materia en el segundo -junto a José GuTIÉRREZ MAESSO que, según señala García de DUEÑAS (2003:106-107), también la impartirá antes incluso de acabar sus estudios-.

Es muy significativo también que parte de las conferencias y proyecciones presentadas por FULCHIGNONI fueran celebradas en las instalaciones del CSIC. De hecho, antes de la organización del Departamento de Filmología, puede apreciarse una creciente atención a la pantalla cinematográfica por parte de la institución, sobre todo a través de la revista Arbor. Los primeros textos sobre cine aparecidos en esta publicación flirtean con las posiciones reaccionarias. Así sucede con el extenso artículo "Las películas 'psicológicas"' (1948), en el que Miguel Siguán detecta un aumento del in-

${ }^{6}$ Como el dedicado a René Clair entre marzo y abril de 1951, que será reseñado por Paulino GARAGORRI en Índice (1951). Según el autor, "la Filmología ha nacido con la inédita pretensión de descubrir científicamente las coordenadas invariantes de esa múltiple realidad humana en que consiste el fenómeno de la visión cinematográfica". Reconoce, sin embargo, que las actividades de la Asociación Española de Filmología están muy lejos de las iniciativas desarrolladas por Cohen-Seat en Francia, aunque es posible que la futura creación de un departamento dedicado a ella en el CSIC permita igualarlas.

$7 A B C, 2$ de diciembre de 1949. 
terés de los espectadores por las películas con personajes tortuosos y resentidos, con enfermos mentales, en las que se insiste "en el hecho morboso psicológico". La consecuencia es una divulgación errónea de la psicología, pues las enfermedades aparecen adaptadas a las necesidades de la intriga y, dada la influencia del cine, existe el peligro de "acostumbrarnos a considerar conductas antinaturales e inmorales como si fuesen perfectamente normales" y muy atractivas. Es el caso de Perdición (Double Indemnity, Billy Wilder, 1944). También cercanos a esta postura son los textos de José Luis PINILLOS en las secciones culturales de la revista, desde los que insistirá en la necesidad de que la crítica de cine señale los valores éticos de cada film o insistirá en la nefasta repercusión del cine sobre la juventud ${ }^{8}$. Más interesantes y ponderadas son las colaboraciones de José GUTIÉRREZ MAESSO, encargado entre abril y diciembre de 1950 de la "Crónica cinematográfica" insertada en este último suplemento. El autor mostrará un mayor conocimiento del medio, además de situar sus críticas y reflexiones en el paradigma crítico que pronto se institucionalizará, caracterizado por el rechazo al cine español del momento, en especial las producciones históricas -Pequeñeces (1950a) y Agustina de Aragón (1950f), ambas de Juan de Orduña-y la atención al neorrealismo, y en concreto a Ladrón de bicicletas (Ladri di biciclette, Vittorio de Sica, 1948) (1950c). Lo interesante es que también dedicará algunas páginas a la Filmología en los números 54 (1950b) y 55-56, recogiendo en este último una sucinta reseña de la celebración de la I Semana Internacional de Filmología, organizada por la AEF y con la asistencia de CoHEN-SeAt, Mario Verdone y Albert Michotte (1950d), y los primeros pasos dados en la creación de un Departamento de Filmología en el CSIC (1950e).

Con estos antecedentes, en 1951 comienza a organizarse el Departamento de Filmología bajo la dirección de Guillermo de Reyna, constituyendo la primera entrada en el ámbito académico del cine más allá de la escuela profesional. El Departamento constará, al menos en proyecto, de las secciones de Filmología y Documentación Cinematográfica y de Realizaciones Cinematográficas.

La primera, en estrecha conexión con el Instituto San José de Calasanz de Pedagogía y el Departamento de Psicología Experimental del Instituto Luis Vives de Psicología, tendrá por objetivo el análisis de los aspectos psicológicos y pedagógicos del cine, la elaboración de guiones y proyectos de películas científicas, docentes o de arte y la organización de una biblioteca especializada y una cinemateca que recogerá el mayor número posible de títulos de este género. Esta sección también programará la realización de un censo de películas científicas y docentes realizadas en el mundo, además de su localización. Como puede apreciarse, sus actividades van más allá del análisis de las películas o la situación espectatorial para proponer la realización de determinados proyectos. Su ejecución correrá a cargo de la Sección de Realizaciones Cinematográficas. Se propone también el establecimiento de colaboraciones con la

$8 \mathrm{Su}$ pesimismo respecto al cine puede apreciarse en sus crónicas "El cine en estos meses" (1948) y "Dos páginas sobre cine" (1949), considerando la mayor parte de las películas estrenadas en estos momentos evasivas, disolventes de los principios morales, desmedidas en su fantasía o intrascendentes. 
Sección de Cine de la UNESCO y la Oficina Católica Internacional del Cine, así como intentar la participación en todos los congresos sobre el empleo del cine con fines educativos que vayan convocándose. El Departamento de Filmología permanecerá activo entre noviembre de 1952 -fecha oficial de su constitución- y mediados de los años sesenta, formando parte del mismo el ya citado Guillermo de Reyna, Julián JUEZ VicenTE, José Agüeras Rubio o Antonio Pastor Bela, además de contar durante sus primeros años con un comité asesor formado por Juan García Yagüe, Manuel Hernández Sanjuán, fray Mauricio de BEGOÑA, José Germain y Victoriano López García.

Pese a los grandes objetivos marcados, que sólo llegarán a desarrollarse con cierta repercusión en los primeros años de su actividad, el departamento centrará sus actividades fundamentalmente en la organización de ciclos, seminarios y cursos orientados a los profesores y educadores -sería el caso del Aula de Cine Educativo celebrada en 1955 o, también a mediados de los años cincuenta, las "Jornadas de Estudio del Cine para Niños"-, además de la participación en otras muchas ajenas al departamento de carácter nacional o internacional, y proyectos como un plan de cine educativo que estudiará los antecedentes de este cine y dará lugar a la organización del Servicio de Cine Educativo del Ministerio de Educación Nacional (vid. Juez Vicente, 1953). También destacará la publicación de artículos sobre cine infantil y educativo en publicaciones como Revista Internacional del Cine, Otro Cine o Revista de Educación. Al menos por lo que puede deducirse de los anuarios del CSIC, las actividades del Departamento languidecerían desde 1957 hasta su desaparición casi una década más tarde.

Los intereses del Departamento de Filmología del CSIC estarán orientados hacia la investigación de la influencia de las películas, sobre todo en la infancia, y a sus posibles aplicaciones didácticas. Este será el tema de muchos de los textos inspirados por la nueva disciplina que nutrirán Revista Internacional del Cine, órgano para el mundo hispanohablante de la OCIC y principal medio de divulgación de la Filmología y el pensamiento católico sobre el cine en España durante los años cincuenta. Algunos de estos artículos son muy explícitos a la hora de demandar que los católicos interesados en el cine atiendan a esta nueva aproximación científica a la pantalla. Sucede con "Filmología" (1955), un extenso reportaje sobre el Segundo Congreso Internacional de Filmología, celebrado en La Sorbona en febrero de 1955, y con "Psicología y cine" (1952), de Amédée AYFre y Agostino Gemelli respectivamente. En el primero, tras definir la Filmología como "una orientación común dada a investigaciones muy diversas como consecuencia de su concentración sobre [...] el 'homo cinematograficus"”, AYFrE insiste en que los análisis de contenido -predominantes en la crítica del momento, al menos en España, que atienden más a qué dice una película que al cómo lo dice- deben completarse desde perspectivas estéticas, sociológicas, psicológicas y fisiológicas, lo que permitirá comprender el cine en su justa medida y atender a su efecto sobre los espectadores. AYFRE exige la imprescindible colaboración entre católicos y filmólogos "para impedir que el hombre se haga esclavo de una de sus más fascinantes técnicas, sino que conociéndola mejor, pueda ponerla al servicio de los valores más altos del espíritu".

En el segundo, cronológicamente anterior pero inspirado por los mismos planteamientos, Gemelli cita entre otros a Pudovkin, Gilbert Cohen-Seat o Merleau-Ponty 
en su intento de dilucidar "cuál es la naturaleza del interés suscitado por el espectáculo cinematográfico". Para el autor, la atracción que despierta una película surge de la propia actividad espectatorial, de los procesos que el interlocutor se ve obligado a realizar para interactuar con el film. Conociendo y manejando estas actividades espectatoriales que producen fruición, y por lo tanto atraen al público a los cines, toda película caerá rendida a los pies de los católicos. "Es importante para nosotros, católicos, la determinación del motivo de ese interés, pues ello nos indicará lo que debemos hacer para orientar ese interés hacia el bien y para impedir que sea ocasión de mal", afirma el autor.

En esta línea puede incluirse la exigencia de Leo LUNDERS (1952) de tomar partido por el análisis a la hora de abordar la influencia de la pantalla en los niños y jóvenes, abandonando los simplismos y las ideas preconcebidas, que suelen surgir de tomar casos extraordinarios por generales, pues no hay relación directa, por ejemplo, entre criminalidad o relajación moral y la asistencia a las salas de proyección. El educador católico tiene que colaborar con los científicos sociales para tomar de ellos sus métodos y calibrar bien el efecto de las películas en su público. El primer paso, sin embargo, será analizar los procesos de comprensión de las películas y, a partir de aquí, seleccionar aquellas que pueden visionar los niños en relación con su edad, incluso intentar orientar a los profesionales del cine interesados en realizar películas infantiles (1954). A estas cuestiones, y a las virtudes didácticas que pueden encontrarse en las películas, dedicarán sus reflexiones también A. Alexandre (1954), Enrico FulchigNONI (1955) o Carlos María StAeHLin (1959).

Resulta interesante contrastar estos textos con "Psicología del espectador de cine" (1952), donde Juan Antonio VALLEJo NÁGERA llega a plantearse si la asistencia a los espectáculos, sobre todo por parte de los adolescentes, trastorna la mente o se asiste a ellos porque la mente ya está trastornada, considerando que se producen de alguna manera ambas cosas. El psiquiatra reproduce algunos de los prejuicios sobre el cine, pudiendo ser vehículo de espectáculos crueles y lascivos, síntoma de la decadencia de las culturas y las civilizaciones, y trastornar a los adolescentes, ya que la afición al cine ha demostrado, según el autor, un descenso en el rendimiento escolar y un aumento de los problemas de conducta moral ${ }^{9}$. Es interesante el contraste porque ilustra a la perfección el doble cariz de la reflexión católica sobre el cine expuesta en las páginas de Revista Internacional del Cine, imposible de desprenderse del todo de los concep-

\footnotetext{
9 "El cine es una fuente muy rica de estímulos de la lívido. El problema de poder mantener la castidad está en muy primer término vinculado a la eliminación de los estímulos de esta índole. El adolescente aficionado al cine claudica irremisiblemente en esta materia. Es perfectamente compatible con la salud mental el que, siguiendo las normas de su credo religioso, el adolescente se mantenga casto. Pero el que un adolescente creyente se salte a la torera las normas morales no puede hacerse sin un grave conflicto intrapsíquico de remordimientos, angustia, desprecio de sí mismo, acto que es el camino por el que se llega rápidamente a la neurosis. En esta situación, el adolescente busca consuelo en nuevas actividades sexuales solitarias y en el refugio que le depara el cine. Con lo que se cierra el círculo viciosos del que es extremadamente difícil librarle".
} 
ciones reaccionarias: la primera es analítica, ponderada y católica; la segunda, alejada de la Filmología, está llena de prejuicios y anatemas, de pacata preocupación por la moral sexual, pero bañada de psicologismo. Será la segunda postura, la dogmática y anatematizadora, la que se impondrá finalmente en la publicación, sobre todo cuando comienza a apreciarse que la otra gran baza de la crítica y la reflexión católica sobre el cine, la promoción de las denominadas "buenas películas", ha dado muy pobres resultados $^{10}$.

\section{Crítica. Del nacionalcatolicismo a Bergman}

La incidencia del catolicismo también es determinante en la configuración de los paradigmas críticos de los años cuarenta -la españolidad- y cincuenta -el neorrealismo/neoidealismo-. Es necesario señalar que estos paradigmas nacen de textos que intentan definir qué es el cine y, sobre todo, qué debe ser, de manera que las películas próximas a este objetivo casi siempre inalcanzable serán valoradas de manera positiva. El primero de ellos, la "españolidad" -circunscrito a la evaluación de las películas españolas- viene conformado por un conjunto indefinido de planteamientos en el que aparecen mezcladas apelaciones a un casticismo noventayochista y temas considerados propios, como los encontrados en la historia de España y en la religión católica indiscutiblemente atada a la primera-, sin por esto renunciar a las innovaciones formales provenientes del extranjero.

El caso más significativo es El escándalo (José Luis Sáenz de Heredia, 1943), que será considerada por la crítica, una vez pasada la fiebre militarista de Raza (José Luis Sáenz de Heredia, 1941), la cima de la españolidad al abordar temas tan propios como el donjuanismo, el honor y la superioridad de la moral católica en el laicista e irreverente siglo XIX, articulados a modo de un igualmente autóctono sacramento de la confesión católica. La película recibirá todos los elogios por parte de los críticos, destacando su contenido católico. Según Rafael Urbano (1943), "José Luis Sáenz de Heredia lo que ha hecho es enfocar de cerca, ampliamente, en un maravilloso alarde técnico, aquel sentido íntimo del temor de Dios que corría soterrado bajo la tolerancia y democratización de un siglo [...]. Por eso oscila la fe en ella, desde los primeros fotogramas hasta los últimos, como la luz de una llama que todos los personajes llevasen dentro. [...] Este es el gran acierto ¡Porque ésta es la gran verdad nuestra!’11.

Todo ello, además, a pesar de que fuera la primera película en abordar relaciones adulteras en el marco de la encorsetada moral de posguerra, lo que también contaba con la aprobación de la crítica católica. Así, José CANO (1943), redactor de la publicación católica Ecclesia, la consideraba "un espectáculo fuerte [...], de espantosos desordenes morales. Todo expresado en la pantalla con viveza impresionante. Pero entre la orgía y el vicio se alza la virtud intransigente y heroica y, al final, el arrepentimiento, la absolución de un ministro del Señor [...]. El buen cine no es el cine ñoño

10 Sobre Revista Internacional del Cine véase NiETo FERRANDO, 2009.

11 El comentario de Rafael DE URBANO enfatiza la consustancialidad entre lo nacional y lo religioso, entre España y el catolicismo, que puede aplicarse a la película y está en la base del ideario nacionalcatólico. Véase Alfonso BotTI, 1992: 17 y 141-142. 
y aburrido, sino el que impone el triunfo de la virtud y la moral católicas en todos los problemas de la vida, aun los más escabrosos, que con ese criterio pueden muy bien llevarse a la pantalla" 12 .

En esta apreciación puede observarse un aspecto en el que insistirá mucho la crítica católica con posterioridad, y es la necesidad de valorar películas alejadas de la moralina bondadosa, torpe y pacata. La ruptura de los parámetros morales es la base del conflicto necesario para que la historia de una película pueda desarrollarse. La cuestión no es tanto si se representa o no la inmoralidad o el delito, sino la manera en que es representado, pues de ellos pueden deducirse enseñanzas valiosas: el quebranto del orden moral necesario para despertar el interés del público puede concluir, bien conducido, en la reafirmación de este orden. Pero el criterio a la hora de aceptar lo inmoral ejemplarizante evolucionará con el paso del tiempo, y si en 1943 era El escándalo o a principios de los años cincuenta Balarrasa (José Antonio Nieves Conde, 1950) las películas que conmocionarían positivamente a la crítica católica ${ }^{13}$, incluso serían consideradas el modelo a seguir por un cine inspirado en el catolicismo, poco tiempo más tarde críticos de igual filiación las apreciarán de una beatería sonrojarte, más impresionados por películas como Las noches de Cabiria (Le notti di Cabiria, Federico Fe1lini, 1957).

La apropiación que la crítica católica hará la esta y otras películas de Fellini se inscribe en el marco de las disposiciones de la OCIC sobre la promoción de las denominadas "buenas películas" desde principio de los años cincuenta. Su criterio puede apreciarse muy bien en la justificación de los premios que esta institución concede en los festivales internacionales desde Revista Internacional del Cine, donde Pierre D'ANDRÉ (1955), redactor jefe de la edición francesa de la publicación, señalaba que "no están destinados a recompensar una película religiosa [...], sino películas que puedan contribuir al progreso espiritual y al desarrollo de los valores humanos. [...] La producción que recoja la vida de un santo, no llamará [...] nuestra atención por su tema, sino que es necesario que tenga, además, incontestables cualidades artísticas y que posea un mensaje humano de características lo suficientemente universales, que pueda ser admitido por todos los espectadores, aunque no participen en nuestras convicciones religiosas". Interesa la película que, con independencia de sus intenciones apologéticas, "esté centrada sobre un problema humano, cuya solución se adapte a la moral cristiana (aunque no se haga directamente referencia o llamamiento a ésta) [...]. Provocando la adhesión del público a tal mensaje, sin ungirlo desde un principio con un postulado religioso, se puede esperar que una libre reflexión llevará al espectador a reconocer, más tarde o más temprano, que no hay otro humanismo más auténtico que el humanismo cristiano".

12 Sobre El escándalo y su repercusión en la cinematografía de la primera mitad de los años cuarenta, véase Jorge NiETO FERRANDO (2011).

13 La mojigatería de la que hacía gala Balarrasa fue reconocida por su propio director, que, según señaló, cuando la película fue vista por un dirigente de Acción Católica Francesa, éste no pudo evitar afirmar que "si esto es todo lo que ocurre en España, bendito y feliz país" (Antonio CASTRO, 1974:264). 
La OCIC prescinde, por tanto, de las películas de temática religiosa, las hagiografías o las que aportaban evidentes enseñanzas morales, para asimilar aquellas otras que puedan contener un mensaje aceptable por parte de los católicos, sin ser específicamente católico, y sentirá una especial predilección por encontrar mensajes de este tipo en directores consagrados, prestigiosos o de una amplia proyección. Serán las películas premiadas por esta institución, las que protagonizarán las grandes campañas de promoción de la prensa cinematográfica católica, tanto en la ya citada Revista Internacional del Cine como en Film Ideal o Cinestudio. En la década de los cincuenta a ello hay que añadir la facilidad con la que los críticos católicos pueden hacer suyos los supuestos del paradigma crítico neorrealista hegemónico en estos momentos, incidiendo en determinados aspectos del mismo y haciéndolo evolucionar hacia el denominado 'neoidealismo'.

Este paradigma -que sustenta la descripción, análisis y valoración de los filmsnace de la atención a los debates italianos sobre el neorrealismo a principios de los años cincuenta, tomando como ejemplo sus películas, y más en concreto del deshilvanado pensamiento del guionista italiano Cesare Zavattini. Su apuesta realista por la estética del seguimiento antes que de la reconstrucción de orientación marxista, su asimilación de conceptos provenientes del cristianismo -como el de "solidaridad" o "amor al prójimo"-, atención a la capacidad funcional atribuida a las películas, a la posibilidad de que actúen como revulsivo en el espectador invitándolo a tomar conciencia sobre determinado problema social o humano, tal vez un primer paso para actuar sobre él, o su interés en presentar una perspectiva ética antes que ideológica, permitirá ser empleado por críticos de muy diferente filiación, desde por la izquierda en Objetivo o Cinema Universitario hasta los católicos nacidos del ala derecha de las Primeras Conversaciones Cinematográficas Nacionales de Salamanca, cuyo órgano de expresión será Film Ideal ${ }^{14}$.

Con todo, estos últimos añadirán al neorrealismo el 'neoidealismo'. Javier AGUIRRE (1956) lo considerará un movimiento cinematográfico caracterizado por unos personajes y situaciones que "responden a un concepto idealista del hombre y del ambiente en que se mueve. Esta idealización, este sentimiento de elevación espiritual proviene de un hecho que se repite invariablemente en la historia del arte: la aspiración humana de comunicarse con Dios".

Ahora bien, ello no implica que los films desatiendan las circunstancias históricas y sociales del momento, lo que confirma su convicción de que "el neoidealismo ha nacido de una de las ramificaciones a que ha dado lugar la evolución del neorrealismo [...]. El neorrealismo se ha aferrado siempre a las causas materiales, sin que [...] dejaran de estar estrechamente ligadas a las morales. Ha llegado al espíritu por el camino de la materia. El neoidealismo tiende a penetrar directamente en los problemas espirituales [...]. Los senderos son distintos, aunque el fin venga a ser el mismo". Para los redactores de Film Ideal este neoidealismo tomará cuerpo en la obra de Fellini. La revista llevará a cabo una extensa campaña de promoción de sus películas hasta con-

14 Sobre las Primeras Conversaciones Cinematográficas Nacionales de Salamanca, véase Nieto FerRando y COMPany, 2006. 
vertirlas en referente inapelable de un cine católico que, según se cree, está llegando a configurarse en estos momentos ${ }^{15}$.

Será GARCía Escudero (1957) el encargado de resaltar el valor católico de Fellini en "El neorrealismo y lo sobrenatural". El cineasta es el máximo exponente de la evolución que está sufriendo el cine italiano, "donde se puede vislumbrar una realidad superior a la terrena", y esta es la opción más propia del neorrealismo: "El cine de Fellini es una invocación al amor al prójimo y una denuncia del egoísmo; sus puntos de partida son siempre sociales [...]; y, aunque la proyección colectiva sea en seguida sustituida por la individual [...], no hay dificultad para reconocer el valor social de ese mensaje que se ofrece al individuo [...]. Ese mensaje lo eleva Fellini hasta el plano sobrenatural. [...] Su cine es una esplendorosa manifestación de esa 'otra realidad', de la cual afirma que es compatible con el neorrealismo". Esto puede apreciarse sobre todo en La Strada, "ese Ladrón de bicicletas del reino del espíritu".

Con su realismo hacia arriba o neoidealismo, Fellini ya desborda el neorrealismo exclusivamente material. Pero el elogioso tratamiento que recibe el cineasta concluirá tras la presentación de La dolce vita (1960) en el Festival de Cannes de 1960, donde obtuvo la Palma de Oro. Su ambigüedad era ya demasiado desconcertante. Para los críticos de Revista Internacional del Cine, una de las películas de esta entrega del festival que podían rescatarse era El manantial de la doncella (Jungfrukällan, 1960), de Ingmar Bergman (ORTEGA FRISÓN, 1960) ${ }^{16}$, director desconocido por esas fechas en España y que estaba destinado a convertirse en el sustituto de Fellini en las campañas de promoción de la crítica católica. El arranque de su recepción en estas latitudes coincide con cambios importantes en la crítica católica, que iniciará a principios de los años sesenta su lenta agonía. Esto puede percibirse muy bien en las páginas de Revista Internacional del Cine o de Film Ideal. La primera acaba su vida en 1963 entre diatribas contra la inmoralidad en las películas, alejada ya de todo intento filmológico, y artículos dedicados a un extinto neorrealismo. Por su parte, Film Ideal pronto se deslizará del paradigma católico-neorrealista, que ya deja de funcionar y suena reiterativo, anacrónico y demasiado atado a la retórica clerical, hacia una mayor atención a los nuevos modelos críticos provenientes fundamentalmente de Francia. Esto conduciría al abandono de Pérez Lozano de la revista en 1961. Por estas mismas fechas el co-

15 La revista dedicará una extensa crítica de Juan COBOS a Il Bidone (Almas sin conciencia, 1955), donde recoge, además, las palabras del propio cineasta sobre su concepción del neorrealismo -"El neorrealismo es un estado del alma: es creer en el hombre, en la vida, en sus pasos esenciales, y no solamente materiales y sociales. [...] Para mí el hombre tiene un alma, lo espiritual cuenta tanto como lo demás, y al final de nuestras búsquedas está Dios. Porque tengo este singular defecto: creo en la existencia de Dios..." (1957)-, celebrará en el número siguiente (APA, 1957) el Oscar recibido por La Strada (1954) -que se unía al premio en Venecia y el galardón de la OCIC- y sobre todo promocionará Las noches de Cabiria, película que había recibido la mención especial de la OCIC en el festival de Cannes de 1957. Véanse, entre otros, Félix LANDÁBURU, 1957 y 1958.

${ }^{16}$ Algunos números más tarde, Carlos María Staehlin (1961) confirmará el sentido religioso de la película, que "presenta nada menos que la victoria del cristianismo sobre el paganismo, no por destrucción, sino por conversión, es decir, una victoria según el auténtico espíritu cristiano, gracias a la inmolación de una víctima inocente y a una milagrosa intervención de Dios". 
legio mayor del Opus Dei Monterols de Barcelona publicará Documentos Cinematográficos, pero su componente católico también queda diluido en textos que atienden a la puesta en escena y la autoría, conceptos tomados de la revista Cahiers du cinéma.

La única publicación que continuará vinculada al pensamiento católico con firmeza será Cinestudio, heredera del primer Film Ideal, y como ésta estará fundada por PÉREZ LozANO. La revista seguirá atendiendo a la vieja consigna de promocionar las "buenas películas"; de hecho, son los títulos premiados por la OCIC los que marcan una parte importante de su agenda, algunos de ellos tan destacados y alabados como El evangelio según San Mateo (Il vangelo secondo Matteo, 1964), de Pier Paolo Pasolini. Esta película será presentada como "un magnífico film cristiano hecho por un marxista", y esto sin duda resulta muy valioso para las aspiraciones proselitistas de los católicos interesados en el cine. El extenso y elogioso comentario de Avelino VELASCO, aparecido en el número 28 (1964), arranca destacando los premios que la OCIC le ha concedido, y sobre todo uno muy especial, "el Premio OCIC de los OCICs" -es decir, la película premiada entre las premiadas-, para más adelante resumir los puntos por los que había sido merecedora de este honor: es fiel al evangelio, supera con creces a películas anteriores sobre la vida de Cristo, representa las enseñanzas sociales de la Sagrada Escritura y puede suscitar un rico debate. Todo ello conducía al autor a afirmar que "si nosotros los cristianos no favorecemos la exacta comprensión y el éxito de este film, perderemos una feliz ocasión de apostolado [...] ¿Será mucho aventurar esta conclusión: el film de Pasolini, nacido en una conciencia marxista, es un instrumento apologético digno de servir a la extensión del reino de Dios?". Con todo, la principal virtud de la película era que constituía una "superación feliz del cine religioso blandengue y sensiblero", un replanteamiento de las hagiografías, denostadas hasta el momento por los mismos católicos.

Será, sin embargo, el cine 'trascendente' de Ingmar Bergman, muy alejado en realidad de las aparentes certezas que mostraban las vidas de santos, el que centrará la atención de la revista. Su introducción en España se producirá en el marco de la Semana Internacional de Cine Religioso y de Valores Humanos de Valladolid celebrada en 1960, y en gran medida será debida a la iniciativa del crítico y escritor jesuita Carlos María STAEHLIN ${ }^{17}$. La primera película del cineasta en merecer de manera destacada la atención de Cinestudio es El séptimo sello (Det sjunde inseglet, 1957). En el número 3 aparecerá una entrevista al jesuita y asiduo al festival de Valladolid Jos BuRVENICH (1962b), autoridad en la obra de Bergman -había publicado Ingmar Bergman zoekt de sleutel (1962a)- y el interesante artículo de José Luis Martín Descalzo "El problema de la fe en los personajes de El séptimo sello". Martín Descalzo considera que el tema recurrente en la filmografía de Bergman es "la derrota del racionalismo y

17 Staehlin sería también el responsable de las manipulaciones que sufrirá la banda sonora de sus películas, como ha señalado Juan Miguel COMPANY (1990), para ensalzar, por ejemplo, el milagro divino de El manantial de la doncella o, mediante doblaje, enfatizar la "causa suprema” que rige el destino de Isak Borg en Fresas salvajes (Smultronstället, 1957). El propio crítico (1962) defendería en Film Ideal la fidelidad al original del doblaje en español de El séptimo sello, y concluía señalando que "ignoramos por qué razón muchos quieren negar a Bergman una religiosidad que el mismo confiesa". 
el triunfo de las fuerzas irracionales", y en esta película aparece concretado en la búsqueda infructuosa de pruebas de la existencia de Dios: "El caballero busca el sentido de la vida; busca también -evidentemente- a Dios. Pero [...] no busca la fe en Dios, sino su evidencia". Lo significativo es que El séptimo sello está en sintonía, según el autor, con el triunfo de la irracionalidad en la cultura occidental desde el principio del siglo $\mathrm{XX}$ frente a la fría racionalidad decimonónica. La religión, sobre todo el arte en relación con ella, ha sufrido este cambio,

"y así, frente a un arte religioso [...] cuadriculado, descaradamente apologético [...] hemos asistido en finales del siglo XIX y a lo largo del XX al avance de un arte religioso que $[\ldots]$ ha exaltado los caminos no puramente racionales de lo religioso. Como ejemplo típico de todo ello señalemos que los grandes personajes religiosos de la novela o el cine actuales nunca han destacado por su fuerza apologética, por su personalidad robusta en lo humano, sino por una serie completamente opuesta de factores: su infantilidad, su fuerte debilidad, su misteriosa luz interior, su desconcertante presencia de Dios, hasta desembocar muchas veces [...] en algo que racionalmente podríamos llamar locura".

El ejemplo que señala el autor es el de Gelsomina en La strada (Federico Fellini, 1956), y sin duda su texto muestra una clara justificación de la apertura de la crítica católica a películas alejadas, en principio, de los temas estrictamente religiosos, pero que pueden contener personajes e historias aprovechables.

A partir de aquí, según los críticos de Cinestudio, Bergman reflexionará sobre la búsqueda de la paz espiritual en Fresas salvajes (Moreno, 1963) y el "silencio de Dios" (MARTIN, 1963) en Los comulgantes (Nattvardsgästerna, 1963). Esta última clímax de esta manera de aproximarse a las películas del cineasta sueco-, junto a Como en un espejo (Såsom i en spegel, 1961) o El silencio (Tystnaden, 1963) compondrán una suerte de trilogía sobre "la estructura religiosa de la personalidad humana [...], la vida humana como estructura abierta a los otros y como confrontación con lo trascendente", tal como confirma Antonio Pelayo en el comentario a La Vergüenza (Skammen, 1968) aparecido en el número 76 (1969). Pero la complejidad del cine de Bergman requerirá la instrucción del espectador, más aún cuando comience a eludir si no lo había hecho en todas sus películas- los sentidos que los católicos le atribuyen. Así puede apreciarse en el comentario a El silencio de Jos BURVENICH (1964), donde considera que la polémica que ha suscitado la película es equivalente a la que surgió tras el estreno de La dolce vita, y como en ella fue un visionado pacato, poco instruido, lo que motivó la incomprensión e incluso la irritación de muchos católicos. Ello es debido, afirma Ángel LLORENTE (1964), al erotismo de algunas escenas y a la complejidad de la tesis filosófico-religiosa que contiene, que resume afirmando que Dios existe, porque "El silencio es el mundo sin Dios".

Cinestudio intentará mantener dentro de sus intereses a un cineasta tan prestigioso como Bergman, y ello obligará a emplear grandes dosis de retórica para hacer digeribles aspectos difícilmente aceptables de sus películas. Con todo, tras El silencio la aplicación de sentidos teológicos a su obra irá desapareciendo, incluso es curioso como Adolfo BELLIDO (1968) introduce su comentario a Persona (1966) destacando la capacidad de muchas películas, y en concreto las del sueco, de producir 'lecturas diver- 
gentes', subjetivas, apropiadas por los espectadores, lo que de alguna manera resume la operación llevada a cabo por los católicos con su cine. Lo cierto es que la crítica católica comenzará a considerar que las películas de Bergman entrarán en cuestiones igualmente problemáticas pero sin trascendencias, como la degradación del ser humano en una situación de conflicto bélico en La vergüenza, presentada en el festival de Valladolid de 1969 y que supone para Antonio Pelayo (1969) un giro hacia temas más comprometidos, o el aislamiento y la imposibilidad de entablar contacto con los demás en Pasión (En passion, 1969) (CASTAÑo, 1970). Tras Bergman, los críticos católicos ya no encontrarán cineastas que defender, al menos tan prestigiosos.

\section{Conclusión}

En 1968, con motivo del monográfico que Cinestudio dedicaría al cine religioso, pasada la fijación con Fellini y concluida la apropiación de Bergman y sus dudas por parte de los católicos, José María PÉREz LozANo -uno de los grandes animadores de la crítica católica- achacaría en "Pero ¿por qué ha de haber un cine religioso?" la deferencia que los católicos tuvieron con películas de moralina sencilla o hagiográficas a finales de los años cuarenta y en los cincuenta a la herencia directa de "una cultura cristiana transita de trentos y de 'insignes polígrafos' [Menéndez y Pelayo], de tomismo sin renovar y de hispanidades; una cultura, en España, detenida en sí misma, aldeana, teológicamente algo paleta y cursi. [...] Nuestros planteamientos adolecían de apologética y de moral; nuestra fe era tranquila". Las referencias a la influencia del nacional catolicismo en el juicio de las películas resultan evidentes, pero para el autor también la producción cinematográfica estaba bajo estas influencias: "Nuestro cine sufría, en sí mismo, las mismas consecuencias; el elogiable intento de las obras misionales pontificias -hacer del cine altavoz para las exigencias evangelizadoras de la fenos llevaría, por la poca imaginación de guionistas y realizadores, a un cine monjil y acaramelado -Sor intrépida-, a la pintura de un sacerdocio retórico y convencional La guerra de Dios, Balarrasa- y, finalmente, a una orgía folclórico-religiosa con monjas andaluzas y Padres Pitillos capaces de enfriar la fe de los más creyentes. [...] Y aún faltaba por llegar el cine hagiográfico, aburrido y convencional, con mal narradas historias de fundadores religiosos"18. Era un cine didáctico, triunfalista, supersticioso y apologético, pero "el éxito de otros films y otros autores es un ejemplo esperanzador de que el hombre sigue preocupado por el problema de Dios". Si bien con esto aludía a algunas películas de Fellini, Bresson, Dreyer, Bergman e incluso Buñuel, llegaba a considerar que para un espectador cristiano todo film podía contener valor religioso y ello "resulta tan evidente en El acorazado Potemkin como en Ordet; la razón de los

18 Las películas citadas por Pérez Lozano y otras tantas adscritas al cine nacional-católico en la década de los cincuenta tuvieron una importante recepción crítica en su momento. Pero destaca sobre todo La Guerra de Dios (Rafael Gil, 1953), cuyo tema de cariz social podía ajustarse al nuevo gusto cinematográfico de un sector importante de la crítica interesado en los planteamientos neorrealistas. A ella se dedicará entre diciembre de 1952 y noviembre de 1953 una importante campaña de promoción que, con reportajes y entrevistas, seguiría la película desde prácticamente el comienzo de su rodaje en revistas como Primer Plano, Cine Mundo, Fotogramas, Imágenes y Revista Internacional del Cine. 
marineros sublevados es tan válida como el milagro de Dreyer". Con sus afirmaciones, PÉREZ LOZANO esbozaba el trayecto que la crítica católica había seguido desde la inmediata posguerra, así como la necesidad de ampliar sus horizontes, de adecuarse a los tiempos para seguir existiendo como opción viable de aproximación a las películas, de buscar allí donde no existían valores fílmicos asumibles desde sus puntos de vista, incluso de recular en sus posiciones para comenzar a aceptar lo anatematizado poco tiempo antes ${ }^{19} \mathrm{y}$, al mismo tiempo, rechazar lo considerado loable por su carácter excesivamente beato. Junto al intento de controlar el cine, que había alcanzado su cima con las reflexiones filmológicas y su esfuerzo por desvelar los secretos encerrados en la especial relación que una película mantenía con su espectador, la crítica católica buscó hacer suyo un cine que siempre acabaría escapándosele.

\section{Referencias bibliográficas}

AGUIRRE, Javier (1957): "El cine y sus estilos”. Film Ideal, núm. 4.

ALEXANDRE, A. (1954): “Cine y psicología infantil”. Revista Internacional del Cine, núm. 10.

ANDRÉ, Pierre d'(1955): "El premio de la OCIC". Revista Internacional del Cine, núm. 19.

AYFRE, Amédée (1955): "Filmología”. Revista Internacional del Cine, núm. 15-16.

BEGOÑA, Mauricio de (1953): Elementos de Filmología. Madrid, Morata.

BELLIDO, Adolfo (1968): "Persona, de Ingmar Bergman”. Cinestudio, núm. 66.

BOTTI, Alfonso (1992): Cielo y dinero. El nacional catolicismo en España (18811975), Madrid, Alianza.

BURVENICH, Jos (1962a): Ingmar Bergman zoekt de sleutel. Tielt, Lannoo.

BURVENICH, Jos (1962b): “Bergman”. Cinestudio, núm. 3.

BURVENICH, Jos (1964): “El silencio, de Ingmar Bergman”. Cinestudio, núm. 21.

CANO, José (1943): “El escándalo”. Ecclesia, núm. 119.

CASTAÑO, Adolfo (1970): “A Passion. Ingmar Bergman”. Cinestudio, núm. 85.

CASTRO, Antonio (1974): El cine español en el banquillo. Valencia, Fernando Torres.

COBOS, Juan (1957): “Almas sin conciencia”. Film Ideal, núm. 6.

COHEN-SEAT, Gilbert (1946): Essai sur les principes d'une philosophie du cinéma. Paris, Presses universitaires de France.

COMPANY, Juan Miguel (1990): Ingmar Bergman. Madrid, Cátedra.

${ }^{19}$ Así sucedería, por ejemplo, con Nazarín, que en este mismo número monográfico recibirá la atención de José Luis GARCi y Ángel Llorente con motivo de la Mención Especial en la Semana Internacional de Cine Religioso y de Valores Humanos de Valladolid en 1968 y la concesión del premio convocado por la propia revista en este mismo certamen. 
DÍEZ PUERTAS, Emeterio (2002): El montaje del franquismo. La política cinematográfica de las fuerzas sublevadas. Barcelona, Laertes

FRIEDMANN, Georges y MORIN, Edgar (1952): "Sociologie du cinéma". Revue Internationale de Filmologie, núm. 10.

FRIEDMANN, Georges y MORIN, Edgar (1955): "De la méthode en sociologie du cinéma". Actes du II Congrès Internationale de Filmologie, Paris, La Sorbonne.

FULCHIGNONI, Enrico (1955): "Filmología y psicología infantil". Revista Internacional del Cine, núm. 20.

GARAGORRI, Paulino (1951): “El 'caso Rene Clair”. Índice, núm. 40.

GARCI, José Luis y LLORENTE, Ángel (1968): “Sobre Luis Buñuel y su Nazarín”. Cinestudio, núm. 69.

GARCÍA ESCUDERO, José María (1957): "El neorrealismo y lo sobrenatural”. Film Ideal, núm. 13.

GARCÍA DE DUEÑAS, Jesús (2003): José Gutiérrez Maesso, el número 1. Badajoz, Diputación de Badajoz.

GEMELLI, Agostino (1952): "Psicología y cine". Revista Internacional del Cine, núm. 2.

GUTIÉRREZ MAESSO, José (1950a): "Crónica cinematográfica”. Arbor, núm. 52.

GUTIÉRREZ MAESSO, José (1950b): "El interés teorético por el cine”. Arbor, núm. 54.

GUTIÉRREZ MAESSO, José (1950c): “Ladrón de bicicletas". Arbor, núm. 55-56.

GUTIÉRREZ MAESSO, José (1955d): "Semana Internacional de Filmología”. Arbor, núm. 55-56.

GUTIÉRREZ MAESSO, José (1955e): "El Departamento de Filmología del Consejo Superior de Investigaciones Científicas”. Arbor, núm. 55-56.

GUTIÉRREZ MAESSO, José (1950f): “Agustina de Aragón”. Arbor, núm. 59.

JUEZ VICENTE, Julián (1953): "Sugerencias para un plan de cine educativo". Revista de Educación, núm. 12.

LANDÁBURU, Félix (1957): "Con Fellini y con Cabiria en Génova", Film Ideal, núm. 9.

LANDÁBURU, Félix (1958): "Esta es mi Cabiria”, Film Ideal, núm. 20.

LLORENTE, Ángel (1964): “Más sobre El silencio". Cinestudio, núm. 21.

LOWRY, Edward (1985): The Filmology Movement and Film Study in France. Ann Arbor (Michigan), UMI Research Press.

LUNDERS, Leo (1952): "Influencia del cine en la infancia". Revista Internacional del cine, núm. 6.

LUNDERS, Leo (1954): "El lenguaje cinematográfico y los niños". Revista Internacional del Cine, núm. 8. 
MARTIN, Jean (1963): “Los comulgantes, otra película con problema, de Ingmar Bergman”. Cinestudio, núm. 7.

MARTÍNEZ BRETÓN, Juan Antonio (1988): La iglesia católica en la cinematografía española (1951-1962). Madrid, Harofarma.

MICHOTTE, Albert (1948): "Le caractère de 'réalité' des projections cinématographiques". Revue Internationale de Filmologie, núm. 2-4

MICHOTTE, Albert (1953): "La participation émotionnelle du spectateur à l'action représentée à l'écran". Revue Internationale de Filmologie, núm. 13.

MORENO, Fernando (1963): “Fresas salvajes en opinión de Según F. Moreno". Cinestudio, núm. 7.

NIETO FERRANDO, Jorge (2009): Cine en papel. Cultura y crítica cinematográfica en España (1939-1962). Valencia, Ediciones de la Filmoteca.

NIETO FERRANDO, Jorge (2011): "El escándalo. Atracciones, confesiones y españolidad”, en CASTRO DE PAZ, José Luis y NIETO FERRANDO, Jorge (coords.): El destino se disculpa. El cine de José Luis Sáenz de Heredia. Valencia, Ediciones de la Filmoteca.

NIETO FERRANDO, Jorge y COMPANY, Juan Miguel (coords., 2006): Por un cine de lo real. Cincuenta años después de las "Conversaciones de Salamanca". Valencia, Ediciones de la Filmoteca.

ORTEGA FRISÓN, Orencio (1960): “Cannes”, Revista Internacional del Cine, núm. 36-37.

PELAYO, Antonio (1969): “La vergüenza, de I. Bergman”. Cinestudio, núm. 76.

PÉREZ LOZANO, José María (1968): "Pero ¿por qué ha de haber un cine religioso?”. Cinestudio, núm. 69.

PINILLOS, José Luis (1949) "Dos páginas sobre cine”. Arbor, núm. 38.

PINILLOS, José Luis (1948): “El cine en estos meses”. Arbor, núm. 31-32.

PÍO XII (1955a): "Características del Film Ideal”. Revista Internacional del Cine, núm. 17-18.

PÍO XII (1955b): "El cine debe estar al servicio del hombre". Revista Internacional del Cine, núm. 21-22.

PÍO XII (1957): “Carta Encíclica 'Miranda prorsus' sobre el cine, la radio y la televisión”. Revista Internacional del Cine, núm. 30.

REY, A. (1954): “La perception d'un ensemble de déplacements". Revue Internationale de Filmologie, núm. 17.

ROMANO, Dario (1965): L'esperienza cinematografica. Florencia, Barbera.

S. G. (1963): "Frente cerrado contra el fango". Revista Internacional del Cine, núm. 42.

SIGÁN, Miguel (1948): "Las películas 'psicológicas”". Arbor, núm. 25 
STAEHLIN, Carlos María (1959): "Cine para menores. Historia y problema". Revista Internacional del Cine, núm. 34.

STAEHLIN, Carlos María (1961): "El manantial de la doncella (Jungfrukällan)”. Revista internacional del Cine, núm. 40.

STAEHLIN, Carlos María (1962): "Nota sobre los diálogos los diálogos de El séptimo sello". Film Ideal, núm. 89.

URBANO, Rafael (1943): "El triunfo de la fe española". Primer Plano, núm. 160.

VALLEJO NÁGERA, Juan Antonio (1952): "Psicología del espectador de cine". Revista Internacional del Cine, núm. 2.

VELASCO, Avelino (1964): "El Evangelio según san Mateo, de Pier Paolo Pasolini. Un magnífico film cristiano hecho por un marxista". Cinestudio, núm. 28.

VV. AA. (1959): "Las películas italianas rechazadas por las salas católicas raramente consiguen amortizar su coste". Revista Internacional del Cine, núm. 35.

WALLON, Henri (1953): "L'acte perceptif et le cinéma". Revue Internationale de Filmologie, núm. 13.

ZAZZO, René y ZAZZO, Bianka (1949): “Une expérience sur le compréhension du film". Revue Internationale de Filmologie, núm. 5.

ZAZZO, René y ZAZZO, Bianka (1949) "Niveau mental et compréhension du cinéma". Revue Internationale de Filmologie, núm. 5. 